Pesq. Vet. Bras. 30(3):255-259, março 2010

\title{
Intoxicação espontânea e experimental por Brachiaria radicans (tanner-grass) em bovinos ${ }^{1}$
}

\author{
Aldo Gava ${ }^{2}$, Márcia Regina Simone de Deus ${ }^{3}$, José Volni Branco ${ }^{4}$, Ademir \\ José Mondadori e Angelica Barth ${ }^{6}$
}

\begin{abstract}
Gava A., Simone de Deus M.R., Branco J.V., Mondadori A.J. \& Marth A. 2010. [Natural and experimental poisoning by Brachiaria radicans (tanner grass) in cattle.] Intoxicação espontânea e experimental por Brachiaria radicans (tanner-grass) em bovinos. Pesquisa Veterinária Brasileira 30(3):255-259. Centro de Ciências Agroveterinárias, Universidade de Desenvolvimento de Santa Catarina, Av. Luiz de Camões 2009, Lages, SC 88520-000, Brazil. E-mail: a2ag@ cav.udesc.br

Brachiaria radicans is a grass that grows well on humid soils. In Santa Catarina, it is found mainly in the valleys of the Tubarão and Itajaí rivers. When eaten by cattle in large amounts induces hemolytic anemia, hemoglobinuria, diarrhea and even death. The objective of this study was to evaluate epidemiologic, clinical and pathological data of the intoxication caused by $B$. radicans in cattle. The plant was administered to 12 cattle in doses of $50-100 \%$ of the diet. The animals that received $100 \%$ of $B$. radicans, grown on peaty soils, showed hemoglobinuria, diarrhea and dark red mucous membranes; they recovered when ingestion of the grass was discontinued. Blood and urine tests revealed anemia, hemoglobinuria and proteinuria. Histopathology of organs collected from cattle that died from spontaneous poisoning revealed hepatic centrolobular and paracentralr coagulative necrosis and hemoglobinuric nephrosis. B. radicans proved toxic for cattle only when it grows on fertile soils and is ingested as $100 \%$ of the diet.
\end{abstract}

INDEX TERMS: Poisonous plants, Brachiaria radicans, Gramineae, plant poisoning, cattle, hemolytic anemia.

RESUMO.- Brachiaria radicans (tanner-grass,) cresce bem em solos úmidos. Em Santa Catarina é encontrada principalmente nas regiões dos vales dos rios Tubarão e Itajaí. Quando ingerida em grandes quantidades pelos bovinos induz anemia hemolítica, hemoglobinúria, diarreia e pode evoluir para a morte. O objetivo deste trabalho foi avaliar os dados epidemiológicos e clínico-patológicos causados por $B$. radicans em bovinos. A planta foi admi-

\footnotetext{
${ }^{1}$ Recebido em 27 de junho de 2009.

Aceito para publicação em 13 de dezembro de 2009

${ }^{2}$ Laboratório de Patologia Animal, Centro de Ciências Agroveterinárias (CAV), Universidade de Desenvolvimento de Santa Catarina (UDESC), Av. Luiz de Camões 2090, Lages, SC 88520-000, Brasil. ${ }^{*}$ Autor para correspondência: a2ag@ cav.udesc.br

${ }^{3}$ Acadêmica (in memoriam) do Curso de Medicina Veterinária, CAVUDESC, Lages, SC. Bolsista de Iniciação Científica do CNPq.

${ }^{4}$ Veterinário autônomo, .Cooperativa Agropecuária, Rua Marechal Deodoro 573, Cx. Postal 95, Centro, Tubarão, SC 88701-010, Brasil.

${ }^{5}$ Departamento de Patologia Veterinária, Instituto de Ciências Agrárias e Medicina Veterinária, Universidade de Alfenas (Unifenas), Rod. MG 179 Km 0, Campus Universitário, Alfenas, MG 37130-000, Brasil.
}

nistrada a 12 bovinos em doses de $50-100 \%$ da dieta. Os animais que receberam uma dieta que consistia de $100 \%$ da planta, originária de solos turfosos, mostraram hemoglobinúria, diarreia, mucosas vermelho-escuras e recuperação após suspensão da ingestão da planta. Exames de sangue e urina revelaram anemia, hemoglobinúria e proteinúria. A histopatologia de material coletado de bovinos que morreram pela doença espontânea, revelou necrose hepática coagulativa e paracentral e nefrose hemoglobinúrica. $B$. radicans mostrou ser tóxica para bovinos somente quando cresce em solos férteis e se consistir de $100 \%$ da dieta.

TERMOS DE INDEXAÇÃO: Plantas tóxicas, Brachiaria radicans, Gramineae, intoxicação por planta, bovinos, anemia hemolítica.

\section{INTRODUÇÃO}

Brachiaria radicans (tanner-grass) (Fig.1) é uma gramínea encontrada em vários estados brasileiros, principalmente da região litorânea e caracteriza-se por ser uma planta invasora que se desenvolve rapidamente em solos úmidos 


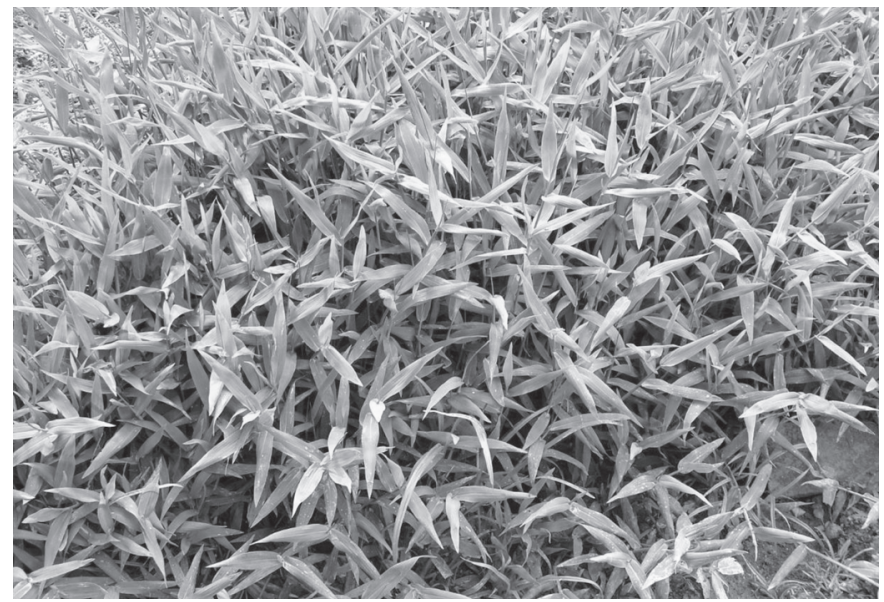

Fig.1. Brachiaria radicans, no município de Tubarão, SC.

(Lorenzi 1982, Kissmann 1997). Em Santa Catarina a planta é encontrada principalmente na região dos vales dos rios Tubarão e Itajaí. Por ter ótima palatabilidade é ingerida em grande quantidade pelos bovinos. Alguns criadores da região relacionam essa planta com uma doença de bovinos caracterizada por urina escura e morte. Com a finalidade de definir o quadro clínico e patológico de uma doença hemolítica que ocorre na região litorânea do estado de Santa Catarina e sua possível relação com a ingestão de $B$. radicans foi realizado levantamento de históricos e foram conduzidos experimentos com essa planta em bovinos.

Na literatura há poucas referências sobre intoxicação por B. radicans. Na Costa Rica, Villalobos et al. (1981) citam $B$. radicans como responsável por perdas econômicas em bovinos. No Brasil a intoxicação por $B$. radicans foi diagnosticada pela primeira vez, no estado de São Paulo, em bovinos que pastoreavam em pastagens constituídas exclusivamente por esta planta (Andrade et al. 1971a, Rosenfeld et al. 1971). Os sinais clínicos são principalmente urina de coloração escura e em jatos, fezes semi-pastosas, ou, diarreia, perda de peso, mucosas pálidas, respiração acelerada. Esses sinais podem se agravar e e terminar com a morte ou, desaparecer rapidamente quando a planta é retirada da alimentação (Rosenfeld et al. 1971).

O principio tóxico responsável pela enfermidade produzida por $B$. radicans não está definido. Níveis elevados de nitratos foram encontrados na planta (Andrade et al. 1971b, Villalobos et al. 1981) e no soro de bovinos intoxicados por essa planta (Andrade et al. 1971b). Foi levantada a hipótese de que a toxicidade da planta seria devida a um mecanismo semelhante ao que ocorre na intoxicação por Brassica sp. Nesse gênero a toxicidade se deve à presença de S-metilcisteína-sulfóxido, um composto não tóxico, que, pela ação de micro-organismos do rúmen, transforma-se em dimetilssulfureto, que causa hemólise (Gava 1993).

As principais lesões macroscópicas são coloração vermelho marrom da conjuntiva e de serosas intestinais, rins tumefeitos e de coloração escura e incoagulabilidade sangüínea. Pela microscopia observa-se necrose hepática centrolobular e paracentral, e nos rins há nefrose difusa acompanhada por esférulas hialinas no citoplasma do epitélio tubular e cilindros hialinos na luz dos túbulos (Gava 1993).

\section{MATERIAL E MÉTODOS}

Para levantamento de históricos e observações sobre a presença de Brachiaria radicans, foram visitadas 20 propriedades rurais do Vale do Rio Tubarão envolvendo os municípios de Tubarão, Gravatal, Jaguaruna e Imaruí. Também foram conduzidos exames clínicos em bovinos com manifestação de hemoglobinúria e realizada necropsia de três animais suspeitos de intoxicação por $B$. radicans. Fragmentos de pulmão, coração, fígado, rim, tubo digestório, baço, linfonodos, músculo esquelético e sistema nervoso central foram fixadas em formol a $10 \%$ e processadas rotineiramente para exame histológico.

Para verificação da toxicidade de $B$. radicans foi utilizada a planta de uma área com solo turfoso e de outra área com solo argiloso. A planta foi fornecida para 12 bovinos, divididos em 6 grupos de 2 animais por um período de 12 dias. Os Grupos I e II foram alimentados, respectivamente, com 50 e $75 \%$ de $B$. radicans e 50 a $25 \%$ de $B$. humidicula e de outras gramíneas nativas. Os grupos restantes foram alimentados com $100 \%$ de $B$. radicans na dieta, sendo que os bovinos do Grupo IV foram mantidos em um piquete formado exclusivamente por $B$. radicans enquanto que os bovinos dos demais grupos foram mantidos estabulados e receberam a planta no cocho. O local de coleta da planta, as doses utilizadas e a forma de alimentação constam no Quadro 1.

Diariamente foram coletadas da jugular amostras de sangue para hemograma e dosagem de bilirrubina e amostras de urina para análise de $\mathrm{pH}$, bilirrubina, urubilinogenio, proteínas, açúcares, corpos cetônicos, hemoglobina, proteínas e nitritos.

\section{Quadro 1. Comportamento clínico dos bovinos que receberam Brachiaria radicans em diferentes percentagens da dieta diária}

\begin{tabular}{|c|c|c|}
\hline $\begin{array}{l}\text { Bovino } \\
\text { e Grupo }\end{array}$ & $\begin{array}{c}\text { Dose }(\%) \text { de } \\
\text { B. radicans }\end{array}$ & Principais alterações clínicas \\
\hline $1,2-I$ & $\begin{array}{l}50^{\mathrm{a}} \text { no } \\
\text { cocho }\end{array}$ & Ausentes \\
\hline $3,4-I I$ & $\begin{array}{l}75^{\mathrm{a}} \text { no } \\
\text { cocho }\end{array}$ & Urina levemente avermelhada \\
\hline $5,6-I I I$ & $\begin{array}{c}100^{a} \text { no } \\
\text { cocho }\end{array}$ & $\begin{array}{l}\text { Urina levemente avermelhada no inicio e for- } \\
\text { temente escura entre os } 10^{\circ} \text { e } 11^{\circ} \text { dias, fezes } \\
\text { pastosas, mucosas vermelha-marrons baixa } \\
\text { coaguabilidade sanguínea, anorexia, cansaço }\end{array}$ \\
\hline 7, 8-IV & $\begin{array}{l}100^{\mathrm{a}} \mathrm{em} \\
\text { pastoreio }\end{array}$ & $\begin{array}{l}\text { Urina levemente avermelhada no inicio (Fig } \\
\text { 4) e fortemente escura (Fig.5) entre os } 7^{\circ} \text { e } \\
8^{\circ} \text { dias, diarréia, mucosas de coloração ver- } \\
\text { melho-marrom, baixa coaguabilidade sangui- } \\
\text { nea, anorexia, cansaço }\end{array}$ \\
\hline $9,10-\mathrm{V}$ & $\begin{array}{l}100^{b} \text { no } \\
\text { cocho }\end{array}$ & Urina levemente avermelhada \\
\hline $11,12-\mathrm{VI}$ & $\begin{array}{l}\text { 100no } \\
\text { cocho }\end{array}$ & Urina leve a moderadamente avermelhada \\
\hline
\end{tabular}

\footnotetext{
a Município de Gravatal, solo turfoso;

b Município de Tubarão, solo argiloso.

c Município de Gravatal, solo argiloso.
} 


\section{RESULTADOS}

\section{Doença espontânea}

Dados obtidos de proprietários do Vale do Rio Tubarão revelaram que frequentemente são observados bovinos com urina de cor âmbar, ou, de cor negra. Quando a urina é fortemente escura, os animais manifestam também diarréia, perda de peso, diminuição do apetite, cansaço, principalmente se movimentados nas horas mais quentes do dia, com eventual morte. Também foi informado que os animais que adoecem gravemente, são na maioria, aqueles trazidos de outras regiões e colocados em áreas constituídas exclusivamente por Brachiaria radicans com desenvolvimento vigoroso.

Clinicamente, foram avaliados vários surtos da doença, que ocorreram em bovinos com idade acima de 6 meses, independente de sexo e raça. O primeiro sinal clínico observado foi urina de cor âmbar, que surgia a partir do $3^{\circ}$ a $4^{\circ}$ dias após a introdução dos animais na pastagem. Em alguns surtos a urina tornava-se cada vez mais escura e a partir do $6^{\circ}$ a $7^{\circ}$ dias era preta e as fezes eram líquidas. Os animais apresentavam ainda salivação, o sangue perdia a viscosidade e tinha coloração vermeIho-marrom, da mesma forma que a coloração da esclera e da conjuntiva. Os animais perdiam peso rapidamente, a respiração era acelerada e agrava-se após a movimentação. A morte ocorria a partir do $3^{\circ}$ a $4^{\circ}$ dia após a urina ficar preta. Os bovinos acometidos gravemente pela doença eram aqueles que pastoreavam em solos turfosos, onde a planta tinha crescimento vigoroso. Além desse fato, foram acometidos bovinos adquiridos de outras regiões e que foram introduzidos em pastagens constituídas exclusivamente por $B$. radicans. A morbidade chegou a $90 \% \mathrm{e}$ a mortalidade foi de 3\%. Quando os bovinos doentes eram retirados das pastagens constituídas por $B$. radicans, a recuperação se dava em poucos dias.

Três bovinos, que morreram naturalmente, foram necropsiados; tinham sangue de coloração vermelho-marrom, com perda da viscosidade e baixa coagulação. A esclera, a conjuntiva e a serosas intestinal eram tingidas por coloração vermelho-marrom. No fígado havia áreas escuras intercalada por áreas levemente amareladas e os rins estavam tumefeitos e escuros. Através da microscopia foi encontrado no fígado necrose coagulativa centrolobular e paracentral (Fig.2) e nos rins havia nefrose caracterizada por tumefação do epitélio tubular, com grande quantidade de gotículas hialinas no citoplasma e cilindros hialinos na luz de túbulos (Fig.3). No fígado de um desses bovinos havia ainda bilestase, ao que tudo indica, por causa intercorrente.

\section{Doença experimental}

Os sinais clínicos foram observados a partir do $4^{\circ}$ dia após início da ingestão da planta, com intensidade máxima entre o $7^{\circ}$ e $8^{\circ}$ dia nos Bovinos 7 e 8 (Grupo IV) e entre o $10^{\circ}$ e $11^{\circ}$ dia nos Bovinos 5 e 6 (Grupo III), quando então os animais com sinais clínicos fortes pararam de

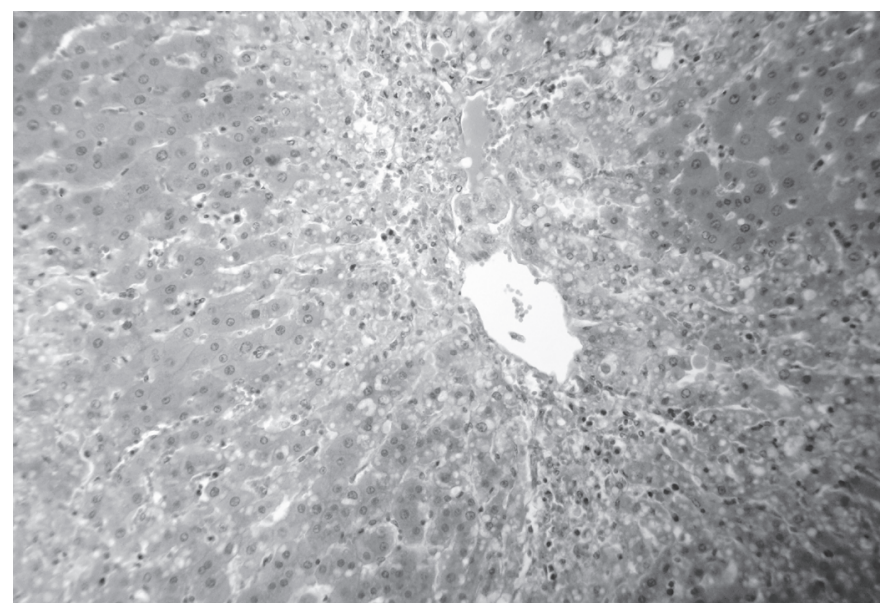

Fig.2. Necrose de coagulação paracentral no fígado de bovino com intoxicação natural por Brachiaria radicans. HE, obj.16x.

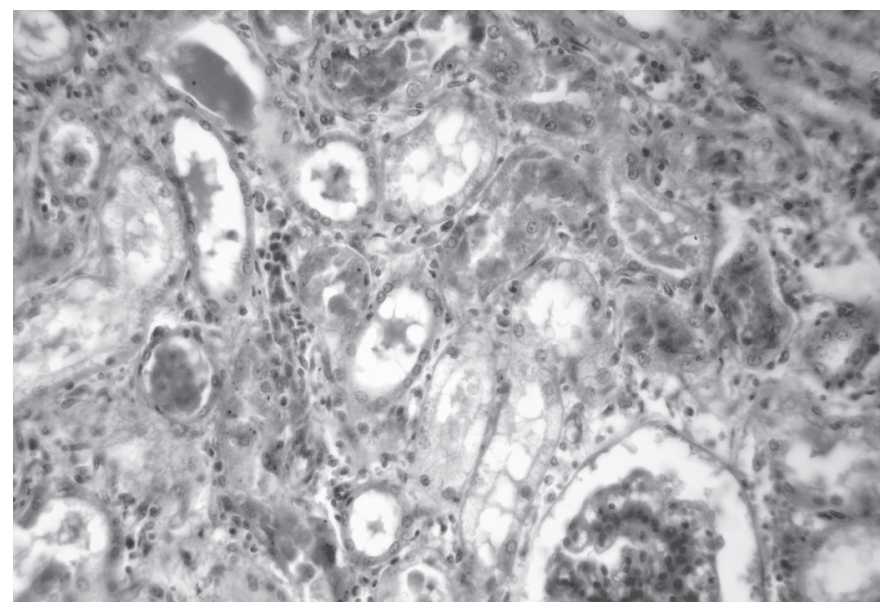

Fig.3. Presença de grande quantidade de gotículas hialinas no citoplasma das células epiteliais e de cilindros hialinos na luz de túbulos uriníferos, na intoxicação natural por Brachiaria radicans em bovino. $\mathrm{HE}$, obj.16x.

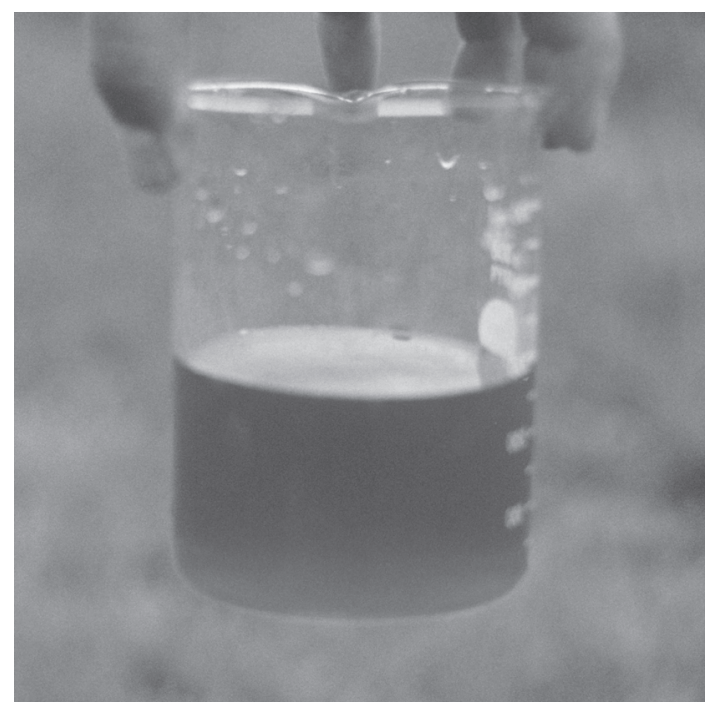

Fig.4. Urina do Bovino 4 coletada no $4^{\circ}$ dia de inicio de ingestão de Brachiaria radicans. 
ingerir a planta, cujo fornecimento neste ponto foi interrompido, retornando a normalidade após o 14º dia do início da ingestão. Os principais sinais clínicos constam no Quadro 1.

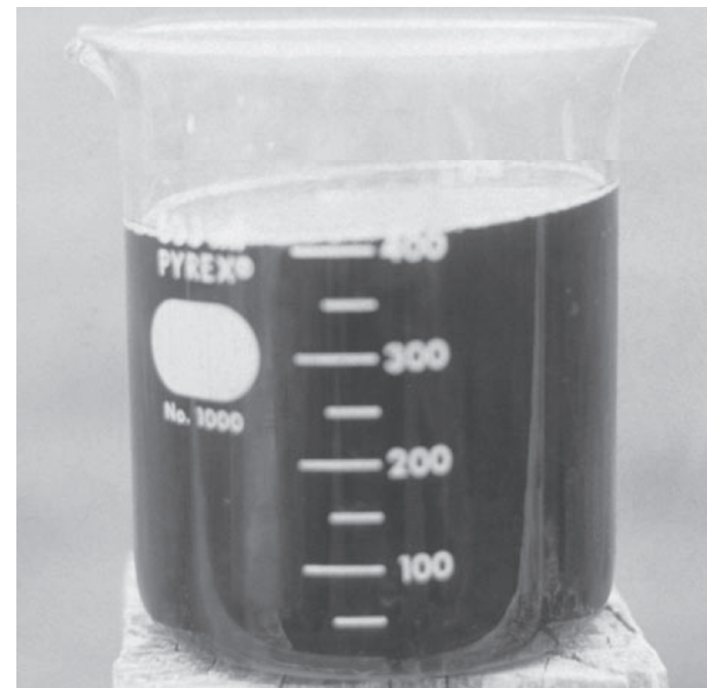

Fig.5. Urina do Bovino 7 coletada no $7^{\circ}$ dia de inicio de ingestão de Brachiaria radicans.

Quadro 2. Resultado da análise de amostras de sangue dos bovinos do Grupo IV, coletadas antes (A), durante ( $8^{\circ}$ dia $=\mathrm{D})$ e após término $\left(4^{\circ}\right.$ dia $\left.=\mathrm{T}\right)$ da ingestão de Brachiaria radicans

\begin{tabular}{|c|c|c|c|c|c|c|c|c|c|}
\hline \multirow[t]{2}{*}{$\begin{array}{l}\text { Bovino } \\
\text { no. }\end{array}$} & \multicolumn{3}{|c|}{$\begin{array}{c}\text { Hematócrito } \\
(\%)\end{array}$} & \multicolumn{3}{|c|}{ Hemoglobina } & \multicolumn{3}{|c|}{$\begin{array}{l}\text { № de hemácias } \\
\text { (milhões } \mathrm{p} / \mathrm{mm}^{3} \text { ) }\end{array}$} \\
\hline & $A$ & $\mathrm{D}$ & $\mathrm{T}$ & $A$ & $\mathrm{D}$ & $T$ & A & $\mathrm{D}$ & $\mathrm{T}$ \\
\hline 1 & 37 & 34 & 36 & 10,2 & 10,5 & 12,3 & 4,8 & 3,7 & 4,0 \\
\hline 2 & 32 & 34 & 37 & 0,0 & 11,0 & 12,0 & 3,5 & 3,7 & 4,1 \\
\hline 3 & 37 & 21 & 29 & 12,0 & 7,0 & 9,3 & 4,1 & 3,2 & 3,2 \\
\hline 4 & 38 & 29 & 24 & 11,8 & 9,6 & 9,0 & 4,2 & 3,8 & 3,6 \\
\hline 5 & 37 & 17 & 29 & 11,8 & 5,6 & 8,0 & 4,1 & 3,2 & 3,2 \\
\hline 6 & 37 & 16 & 20 & 11,0 & 5,0 & 6,5 & 4,5 & 1,7 & 2,0 \\
\hline 7 & 36 & 17 & 24 & 11,3 & 5,2 & 8,0 & 4,4 & 1,8 & 2,6 \\
\hline 8 & 24 & 15 & 21 & 8,0 & 5,0 & 7,0 & 4,6 & 1,6 & 2,3 \\
\hline 9 & 42 & 42 & 40 & 14,0 & 13,4 & 13,0 & 4,6 & 4,6 & 4,4 \\
\hline 10 & 43 & 44 & 41 & 14,0 & 13,3 & 13,1 & 4,7 & 4,8 & 4,5 \\
\hline
\end{tabular}

Os exames de sangue e de urina revelaram alterações significativas nos Bovinos 5, 6, 7 e 8. As análises de $\mathrm{pH}$, urubilinogênio, açúcares, corpos cetônicos e nitritos não mostraram alterações. Os resultados do eritrograma e da bilirrubina total, direta e indireta, e de urina dos bovinos dos Grupos I, II, III, IV e V constam nos Quadros 2 e 3 , respectivamente.

\section{DISCUSSÃO}

Experimentalmente Brachiaria radicans, quando ingerida pelos bovinos em quantidades de $50 \%$ da dieta, não produziu alterações clínicas. Esse resultado está de acordo com as observações efetuadas em propriedades onde os bovinos eram mantidos em áreas com $B$. radicans e outras gramíneas como $B$. humidicula e B. mutica (capimangola), ou, outros tipos de gramíneas nativas.

Os bovinos que receberam $B$. radicans de solos turfosos na proporção de $75 \%$ da dieta, ou, aqueles que receberam a planta de solo argiloso na dose de $100 \%$ da dieta (Bovinos 3 e 4 [Grupo II], Bovinos 9 e 10 [Grupo V], Bovinos 11 e 12 [Grupo VI]), além de eliminar urina avermelhada, não mostraram outros sintomas. Esse quadro clínico foi observado também em casos espontâneos, onde os bovinos eram mantidos em áreas de solo argiloso, cuja pastagem era constituída somente por $B$. radicans.

A forma grave da intoxicação experimental e espontânea por $B$. radicans só foi observada em animais que ingeriram a planta de solos férteis (turfosos), com crescimento vigoroso e em quantidades de $100 \%$ da dieta. Isto pode explicar a ocorrência da doença em algumas propriedades, enquanto que em outras de solos menos férteis (argilosos), mesmo com a predominância da planta, a doença não foi observada. Para a ocorrência da intoxicação espontânea também deve ser considerada a aquisição de animais de outras regiões que chegam com fome e são introduzidos em locais onde $B$. radicans é planta predominante.

$\mathrm{Na}$ intoxicação espontânea por $B$. radicans observouse necrose de hepatócitos das regiões centro-lobular e paracentral. Embora não tão grave como ocorre nas into-

Quadro 3. Valores de bilirrubina total, direta e indireta, no sangue e de proteína e hemoglobina na urina de bovinos, antes $(A)$, durante $\left(8^{\circ}\right.$ dia $\left.=\mathrm{D}\right)$ e $\left(4^{\circ}\right.$ dia $\left.=\mathrm{T}\right)$ após término da ingestão de Brachiaria radicans

\begin{tabular}{|c|c|c|c|c|c|c|c|c|c|c|c|c|c|c|c|}
\hline \multirow{3}{*}{$\begin{array}{c}\text { Bovino } \\
\text { no. }\end{array}$} & \multicolumn{9}{|c|}{ Bilirrubina } & \multicolumn{6}{|c|}{ Urina } \\
\hline & \multicolumn{3}{|c|}{ Total } & \multicolumn{3}{|c|}{ Direta } & \multicolumn{3}{|c|}{ Indireta } & \multicolumn{3}{|c|}{ Hemoglobina } & \multicolumn{3}{|c|}{ Proteína } \\
\hline & A & $\mathrm{F}$ & $T$ & A & $\mathrm{F}$ & $T$ & A & $\mathrm{F}$ & $T$ & A & $\mathrm{F}$ & $T$ & A & $\mathrm{F}$ & $\mathrm{T}$ \\
\hline 1 & 0,9 & 1,0 & 1,0 & 0,2 & 0,2 & 0,2 & 0,7 & 0,8 & 0,7 & $-a$ & - & - & - & - & - \\
\hline 2 & 0,7 & 1,0 & 1,1 & 0,2 & 0,3 & 0,3 & 0,5 & 09 & 0,8 & - & - & - & - & - & - \\
\hline 3 & 1,0 & 1,2 & 1,0 & 0,2 & 0,3 & 0,2 & 0,8 & 0,9 & 0,8 & - & + & - & - & - & - \\
\hline 4 & 0,6 & 2,0 & 1,0 & 0,2 & 0,3 & 0,1 & 0,4 & 1,7 & 0,9 & - & + & _ & - & - & - \\
\hline 5 & 1,2 & 2,6 & 2,0 & 0,3 & 0,2 & 0,2 & 0,9 & 2,4 & 1,8 & - & +++ & - & - & + & - \\
\hline 6 & 0,8 & 2,2 & 1,4 & 0,2 & 0,5 & 03 & 0,6 & 1,7 & 1,1 & - & +++ & - & - & + & - \\
\hline 7 & 0,7 & 6,4 & 5,9 & 0,3 & 0,7 & 0,6 & 0,4 & 5,7 & 5,3 & - & +++ & + & - & +++ & + \\
\hline 8 & 1,1 & 2,8 & 1,2 & 0,2 & 0,2 & 01 & 0,9 & 2,6 & 1,1 & - & +++ & + & - & +++ & - \\
\hline 9 & 0,6 & 2,8 & 1,1 & 0,2 & 0,2 & 0,2 & 0,4 & 2,6 , & 0,9 & - & - & - & - & - & - \\
\hline 10 & 0,4 & 1,5 & 0,9 & 0,2 & 0,2 & 0,2 & 0,2 & 0,7 & 1,3 & - & - & - & - & & \\
\hline
\end{tabular}


xicações por plantas de ação hepatotóxica aguda, esse achado microscópico pode induzir ao erro de diagnóstico. Porém, na intoxicação por $B$. radicans, ao contrário do que ocorre na intoxicação por plantas hepatotóxicas de ação aguda, nas áreas de necrose hepática, não são observadas hemácias o que sugere que a necrose não é resultado do princípio tóxico da planta, mas sim da anóxia associada à anemia hemolítica.

O diagnóstico clínico de intoxicação por $B$. radicans em bovinos deve ser feito através dos dados epidemiológicos, sinais clínicos e a presença da planta em grande quantidade e de crescimento vigoroso. Os dados obtidos de exames de sangue e urina revelaram principalmente anemia, hemoglobinúria e proteinúria. Estes dados podem auxiliar na formação do diagnóstico de intoxicação por $B$. radicans. Porem, as alterações clínicas, a necrose de hepatócitos das regiões centrolobular e paracentral e a nefrose hemoglobinúrica associadas ao pastoreio em locais de $B$. radicans, são suficientes para a confirmação.

A intoxicação por $B$. radicans deve ser diferenciada de outras doenças que cursam com urina escura, principalmente da hemoglobinúria bacilar e babesiose, doenças frequentemente observadas na região de ocorrência de $B$. radicans. Essas duas enfermidades cursam com febre e às vezes icterícia, o que não ocorre com a intoxicação por $B$. radicans. Diagnóstico diferencial também deve ser feito com a intoxicação por Lantana sp., planta muito freqüente na região litorânea do estado e que pode causar urina escura nos bovinos, mas que clinicamente pode ser diferenciada pela fotossensibilização.

$B$. radicans também é citada por alguns autores como planta com teores elevados de nitrato e que a doença por ela produzida poderia estar ligada a este composto químico ou, pela conversão deste no rumem em nitrito (Villalobos et al. 1981 Andrade et al. 1971b). Nos bovinos do presente estudo foi observado que o quadro clínico da doença persiste por vários dias e tem como característica clinica sinais de anemia hemolítica. A intoxicação por nitrato/nitrito tem curso rápido, em geral de poucas horas e nela não ocorrem as alterações observadas na anemia hemolítica da intoxicação causada por $B$. radicans. Dessa forma acredita-se que a enfermidade produzida por $B$. radicans está relacionada a um outro princípio tóxico e não a intoxicação por nitrato/nitrito. Isto também encontra sustentação no fato de que ao exame de urina dos animais em experimentação do presente estudo não foi detectado nitrito.

Como medidas profiláticas à intoxicação a por $B$. radicans é indcada a consorciação desse capim com outras gramíneas, ou, intercalar pastoreios por três dias em áreas com $B$. radicans e três dias ou mais, em áreas com outras gramíneas. No caso de surtos graves da doença, os animais devem ser retirados imediatamente do local, evitando o mínimo de movimentação e manter os mesmos em locais frescos. A transfusão sanguínea pode ser uma boa alternativa para acelerar a melhora do quadro clínico. A recuperação dos animais pode ocorrer em 3-4 dias após a suspensão da ingestão da planta.

\section{CONCLUSÕES}

Bovinos mantidos em pastagens constituídas exclusivamente de Brachiaria radicans com desenvolvimento exuberante, como ocorre nos solos turfosos, desenvolvem alterações clínicas a partir do $4^{\circ}$ dia do início da ingestão; elas se intensificam com a ingestão continuada da planta e se tornam graves a partir dos $7^{\circ}$ a $8^{\circ}$ dias, com a eventual morte do animal.

$B$. radicans quando cresce sobre solos com muita matéria orgânica (solos turfosos), se ingerida pelos bovinos em quantidades de $75 \%$ da dieta pode produzir hemoglobinúria leve. Quadro clínico semelhante pode ser observado também em bovinos alimentados exclusivamente de $B$. radicans, quando esta tem desenvolvimento pouco vigoroso, como ocorre nos solos argilosos.

$B$. radicans, quando ingerida pelos bovinos em quantidades de até $50 \%$ da dieta, não produz alterações clínicas, independente do estado vegetativo da planta.

A morte de bovinos que ingerem grandes quantidades de $B$. radicans pode ser explicada pela hemólise. Essa, por sua vez desencadeia anemia que pode explicar a necrose de coagulação observada no fígado. A hemoglobinúria em decorrência da hemólise produz nefrose hemoglobinúrica agravando ainda mais o quadro clínico.

Nas regiões de solos com muita matéria orgânica e exclusivamente $B$. radicans, sugere-se consorciação desta gramínea com outras forrageiras em pelo menos $25 \%$ da dieta diária.

\section{REFERÊNCIAS}

Andrade S.O., Peregrino C.J.B. \& Aguiar A.A. 1971a. Estudos sobre Brachiaria sp. (Tanner Grass). I. Efeito nocivo para bovinos. Arqs Inst. Biológico, São Paulo, 38(3):135-150.

Andrade S.O., Retz L. \& Velloso C.A. 1971b. Estudos sobre Brachiaria sp. (Tanner Grass). II. Dosagem de nitrato em soro de bovinos. Arqs Inst. Biológico, São Paulo, 38(3):151-161.

Gava A. 1993. Intoxicação por Brachiaria radicans, p.319-322. In: RietCorrea F., Méndez M.C. \& Schild A.L. (Eds), Intoxicação por Plantas e Micotoxicoses. Editorial Hemisfério Sul do Brasil, Pelotas.

Kissmann K.G. 1997. Plantas Infestantes e Nocivas. Tomo 1. 2ª Ed. Editora BASF, São Paulo.

Lorenzi H. 1982. Plantas Daninhas do Brasil. Editora Plantarum, Nova Odessa. 425p.

Rosenfeld G., Reichmann C.E. \& Andrade S.O. 1971. Anemia hemolítica em bovinos alimentados com Brachiaria sp. (Tanner Grass). Arqs Inst. Biológico, São Paulo, 38(4):267-273.

Villalobos J.S., Meneses A.G., León S.C. \& Carballo G.C. 1981. Clinica y patología de la intoxicación con Napper (Tannergrass). Ciencias Veterinarias, Costa Rica, 3(2/3):163-169. 